\title{
Therapeutic Cure of Obesity Hypoventilation Syndrome Resulting in Cure of Obstructive Sleep Apnea and Metabolic Syndrome
}

\author{
Anshul Mittal ${ }^{1}$, Jagdish C Suri ${ }^{2}$, Shibdas Chakrabarti ${ }^{3}$, Vidushi Rathi ${ }^{4}$, Pranav Ish $^{5}$
}

\begin{abstract}
Obesity hypoventilation syndrome $(\mathrm{OHS})$ is a highly underdiagnosed and undertreated condition, especially in developing countries like India. We present a case of a young 26-year-old male with Metabolic syndrome along with severe OSA with OHS, who after weight reduction of 50 kgs over 2 years was practically cured of the same; with no requirement of PAP, insulin and oral medications in follow-up. This case highlights the importance of evaluating obstructive sleep apnea by a phenotypic approach so that appropriate treatment is given.
\end{abstract}

Keywords: Cure, Obesity hypoventilation syndrome, Obstructive sleep apnea.

Indian Journal of Sleep Medicine (2019): 10.5005/jp-journals-10069-0034

\section{INTRODUCTION}

$\mathrm{O}$ besity hypoventilation syndrome (OHS) is a highly underdiagnosed and undertreated condition, especially in developing countries like India. Treatment options include weight reduction, various forms of positive airway pressure (PAP) therapy, bariatric surgery with the limited role of respiratory stimulants. We present a case of a young 26-year-old male with metabolic syndrome along with severe OSA with OHS, who after weight reduction of $50 \mathrm{~kg}$ over 2 years was practically cured of the same; with no requirement of PAP, insulin and oral medications in follow-up.

\section{CASE}

A 26-year-old resident of Delhi, an accountant by profession, presented to sleep clinic of Safdarjung Hospital, with recently diagnosed diabetes mellitus and hypertension. He was morbidly obese with a weight of 140 kgs with a body mass index (BMI) of 42.7. He presented with complaints of excessive day time sleepiness with loud snoring and unrefreshing sleep followed by a headache. Epworth sleepiness scale was 18 . The patient was in type II respiratory failure with po2 of 55 and $\mathrm{pCO}_{2}$ of 60 on room air in arterial blood gas (ABG) analysis. The patient had no history of breathlessness in childhood, seasonal or diurnal variations and had no family history of asthma. Detailed evaluation of the ABG revealed a maintained alveolar-arterial oxygen gradient suggesting hypoventilation being the etiology of hypercapnia and no evidence of ventilation-perfusion mismatch.

There was no personal or family history of smoking, no history of tuberculosis in the past and on the investigation, the patient had a normal chest X-ray with a normal pulmonary function test with no evidence of airway obstruction.
${ }^{1}$ Consultant, ${ }^{2,3}$ Head, ${ }^{4}$ Senior Resident, ${ }^{5}$ Assistant Professor

1,2Department of Pulmonary, Critical Care and Sleep Medicine, JCS Institute of Pulmonary, Critical Care and Sleep Medicine, New Delhi, India ${ }^{3-5}$ Department of Pulmonary, Critical Care and Sleep Medicine, Safdarjung Hospital, New Delhi, India

Corresponding Author: Pranav Ish, Assistant Professor, Department of Pulmonary, Critical Care and Sleep Medicine, Vardhman Mahavir Medical College and Safdarjung Hospital, New Delhi, India, e-mail: pranavish2512@gmail.com

How to cite this article: Mittal A, Suri JC, Chakrabarti S, Rathi V, Ish P. Therapeutic Cure of Obesity Hypoventilation Syndrome Resulting in Cure of Obstructive Sleep Apnea and Metabolic Syndrome. Indian Sleep Med 2019;14(1):18-21.

Source of support: Nil

Conflict of interest: None

Hewas started on parenteral insulin, oral tablet metformin, tablet losartan and counseled for weight reduction. His polysomnography (PSG) was done which showed severe obstructive sleep apnea with prolonged apneas (Graphs 1 and 2) and an expiratory pressure of 14 was titrated to abolish all apneas with an inspiratory pressure of 27 to abolish hypopneas, snoring and to correct the hypoventilation. He was kept on the above-titrated pressure in the hospital and showed significant improvement in arterial blood gas analysis with room air $\mathrm{pO}_{2}$ increasing to 82 and $\mathrm{pCO}_{2}$ decreasing to 40 . The patient was discharged with advice to be compliant with therapy and counseled for weight loss.

The patient had a weight loss of $10 \mathrm{~kg}$ by diet, exercise and treatment in 3 months after which his insulin was tapered and then stopped with $\mathrm{HbA1c}$ of 6.1. The patient was counseled for bariatric

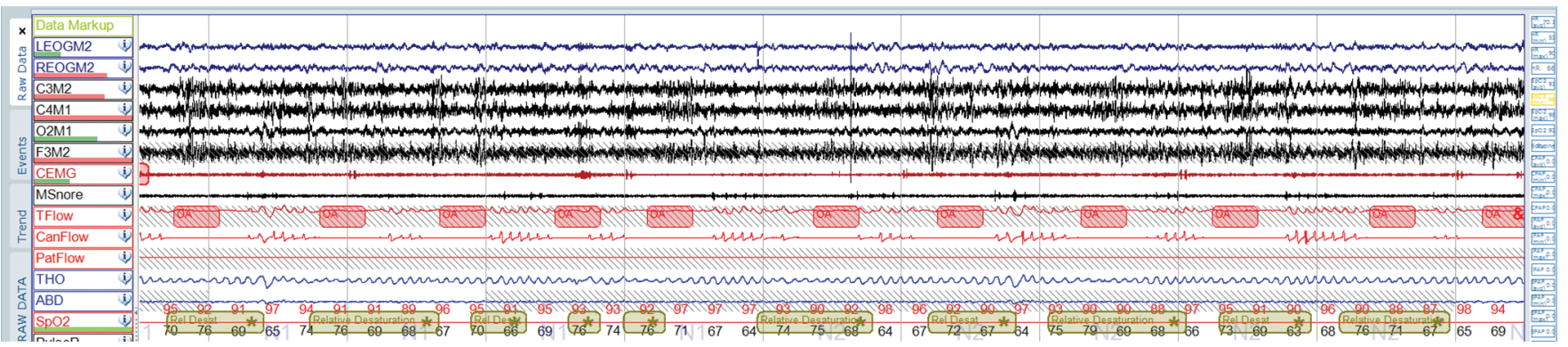

Graph 1: Polysomnography showing severe obstructive sleep apnea

(0) The Author(s). 2019 Open Access This article is distributed under the terms of the Creative Commons Attribution 4.0 International License (http://creativecommons. org/licenses/by/4.0/), which permits unrestricted use, distribution, and non-commercial reproduction in any medium, provided you give appropriate credit to the original author(s) and the source, provide a link to the Creative Commons license, and indicate if changes were made. The Creative Commons Public Domain Dedication waiver (http://creativecommons.org/publicdomain/zero/1.0/) applies to the data made available in this article, unless otherwise stated. 


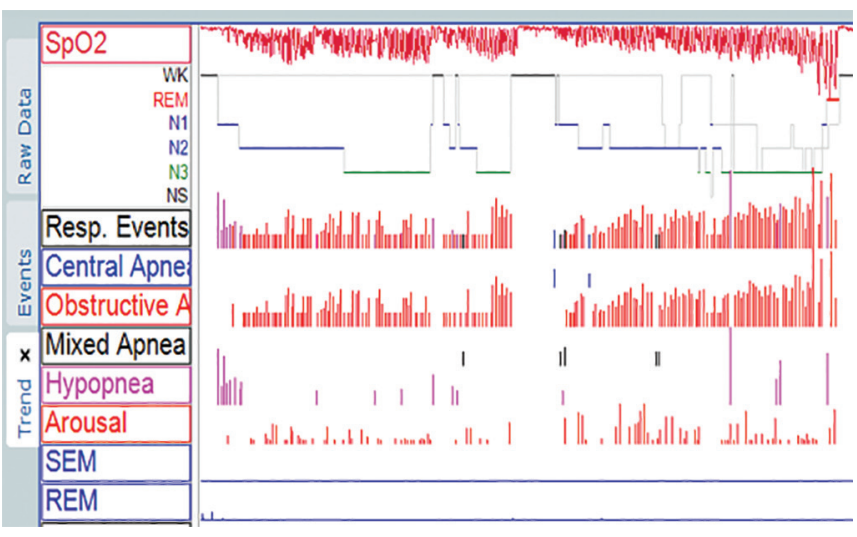

Graph 2: Hypnogram showing severe obstructive sleep apnea along with desaturation with poor sleep quality

surgery in view of morbid obesity, but patient further achieved a $20 \mathrm{~kg}$ weight loss in the next 2 months. His dose of oral hypoglycemic and anti-hypertensive drugs was further tapered.

After 9 months of therapy, the patient presented with a net weight loss of around $45 \mathrm{kgs}$. He used a regular daily exercise plan on his smartphone, followed a low-calorie weight reducing diet chart besides starting cycling and swimming as hobbies.
He did work from home and dedicated all his time to his fitness schedule. There was no pharmacotherapy. He complained of high pressures leading to discomfort with PAP therapy, and a repeat PSG was planned.

Surprisingly, the patient has few hypopneas and no apneas in the repeat PSG (Graph 3). There were minimal desaturations, awakenings and no evidence of hypoventilation as documented by the use of transcutaneous $\mathrm{CO}_{2}$ monitor. On request of the patient, the PAP therapy was discontinued, and the patient is doing well in the past 2 years of follow up with practically only tablet metformin $500 \mathrm{mg}$ once a day. The follow up of the patient is summarized in Table 1.

\section{Discussion}

An OHS is defined as a combination of obesity BMI $>30 \mathrm{~kg} / \mathrm{m}^{2}$ ) with daytime hypercapnia $\left(\mathrm{pCO}_{2}>45 \mathrm{~mm} \mathrm{Hg}\right)$ in the absence of other known causes of alveolar hypoventilation. ${ }^{1}$ Such patients generally also have underlying sleep apnea. Obesity is a risk factor for obstructive sleep apnea/hypopnea syndrome (OSAHS). Some studies have found hypercapnia in 10 to $20 \%$ of OSAHS patients; however, these studies were limited by small sample size, biased recruitment of patients with COPD or severe obesity, and the exclusive enrollment of one gender group and/or ethnic background..$^{2-4}$ Hence, the exact prevalence of OHS is not known. Also, little is known about the

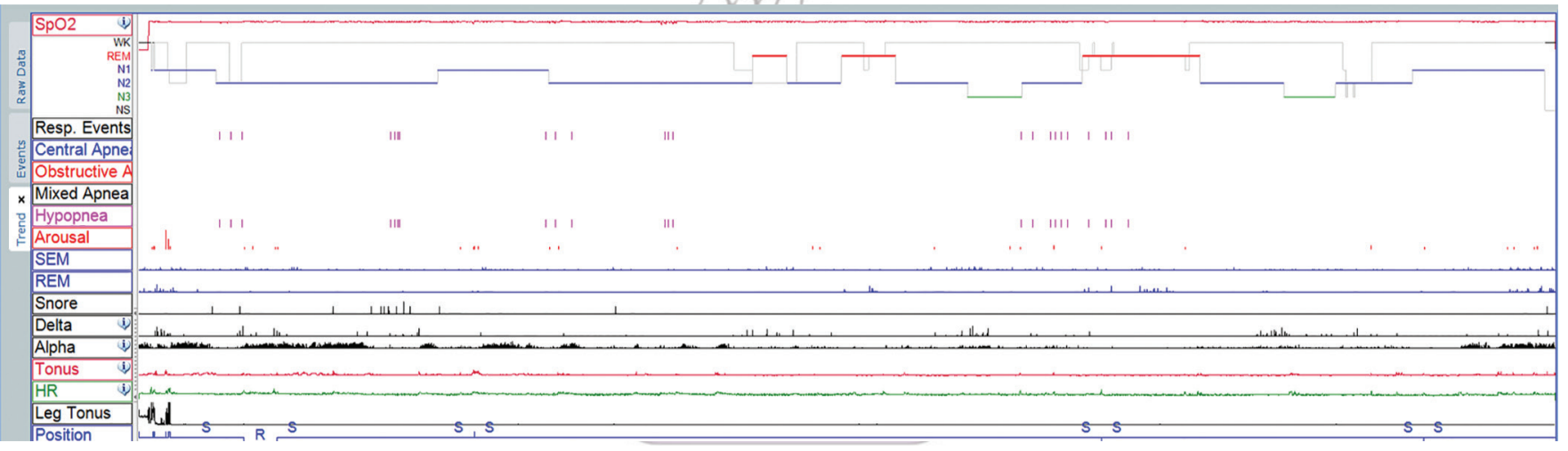

Graph 3: Hypnogram showing resolution of both obstructive sleep apnea and hypoventilation post weight loss

Table 1: Follow-up of the patient and medications

\begin{tabular}{|c|c|c|c|c|c|c|}
\hline Parameter & Admission & Discharge at 1 week & 3-months follow-up & 5-months follow-up & 9-months follow-up & 2 years follow-up \\
\hline Weight & $140 \mathrm{~kg}$ & $137 \mathrm{~kg}$ & $127 \mathrm{~kg}$ & $107 \mathrm{~kg}$ & $95 \mathrm{~kg}$ & $92 \mathrm{~kg}$ \\
\hline BMI & 42.7 & 42.1 & 39.2 & 35 & 33 & 32 \\
\hline BP & $160 / 100$ mm Hg & $136 / 80 \mathrm{~mm} \mathrm{Hg}$ & $118 / 78 \mathrm{~mm} \mathrm{Hg}$ & $118 / 80 \mathrm{~mm} \mathrm{Hg}$ & $122 / 76 \mathrm{~mm} \mathrm{Hg}$ & $120 / 76$ mm Hg \\
\hline $\begin{array}{l}\text { Anti-hypertensive } \\
\text { drugs }\end{array}$ & $\begin{array}{l}\text { 2-diuretic and } \\
\text { ace-inhibitor }\end{array}$ & Same & Diuretic stopped & $\begin{array}{l}\text { Ace-inhibitor dose } \\
\text { decreased }\end{array}$ & All stopped & No drugs \\
\hline $\mathrm{HbA1c}$ & 10.8 & Not done & 6.1 & 5.5 & 5.9 & 6.0 \\
\hline Insulin & Basal glargine & same & tapered & stopped & No insulin & No insulin \\
\hline $\begin{array}{l}\text { Oral hypoglycemic } \\
\text { drugs }\end{array}$ & $\begin{array}{l}\text { Metformin and } \\
\text { sitagliptin }\end{array}$ & same & Same & Sitagliptin stopped & Metformin only & $\begin{array}{l}\text { Metformin OD } \\
\text { only }\end{array}$ \\
\hline PSG-AHI & 102 & - & - & - & 4 & - \\
\hline PAP pressures & Ipap-27 & - & - & - & - & - \\
\hline Epap- 14 & - & same & - & stopped & - & - \\
\hline ABG- $\mathrm{Ph}$ & 7.30 & 7.38 & 7.41 & - & 7.43 & 7.41 \\
\hline ABG- $\mathrm{PO}_{2}$ & 65 & 82 & 88 & - & 89 & 88 \\
\hline ABG- $\mathrm{PCO}_{2}$ & 60 & 40 & 38 & - & 37 & 36 \\
\hline
\end{tabular}


prevalence of OHS in the obese population, irrespective of OSAHS. Current estimates suggest that around 0.3 to $0.4 \%$ of the population may have $\mathrm{OHS}^{5,6}$ Prevalence of OHS is set to increase with rising obesity; therefore, accurate assessment of the prevalence of OHS is critical for planning health services to make provision for this condition. Furthermore, the need for early detection of OHS is clear because the delay in diagnosis and treatment is associated with significant morbidity and mortality. If left untreated, $\mathrm{OHS}$ is associated with a mortality of $23 \%$ at 18 months following discharge from hospital; adequate treatment of OHS reduces this to $3 \%$. In addition, untreated OHS patients are likely to require invasive mechanical ventilation with a longer hospital stay. ${ }^{7}$ The standard assessment to screen for daytime hypercapnia is the measurement of arterial blood gases. It has been suggested that obese patients with hypercapnia have higher BMI, more severe OSAHS, and worse restrictive chest wall mechanics, and higher chronic bicarbonate levels than normocapnic obese patients. $^{5}$

The pathophysiology of OHS is complex, more like a vicious cycle. But effective treatment options are available which block these complex pathophysiolocial pathways at different levels. (Flow chart 1). The root cause is obesity, so treatment for that is most effective, directly inhibiting all further pathways. Pure obesity with OSA leading to OHS without leptin resistance is a pathway as shown in Flow chart 1, which if diagnosed and treate d early, can help in an effective cure.

OSA has been tried to be phenotyped recently to decide the most effective treatment strategy for the same. Unfortunately, there is no consensus, and ultimately therapy remains at the discretion of the doctor and the patient, thus individualized. A hereditary component through genes like ACE, TNF alpha, ADRB2, etc. has long been recognized, but causation has not been proven. Other phenotypes such as craniofacial structural defects, adenotonsillar enlargement, and obesity have been suggested. ${ }^{8}$ The various phenotypes and the treatment options available have been summarized in Table 2.

The importance of phenotyping stems from the very basic concept of different treatment strategies which show a response in their phenotypes. Adenotonsillectomy done early in childhood can prevent physical and mental complications besides correcting OSA in the subgroup of childhood OSA. Macroglossia can be corrected in the majority of patients if appropriate surgeries are carried out. Some phenotypes can, however, be less responsive and

Flow chart 1: Obesity hypoventilation syndrome: pathophysiology and treatment options

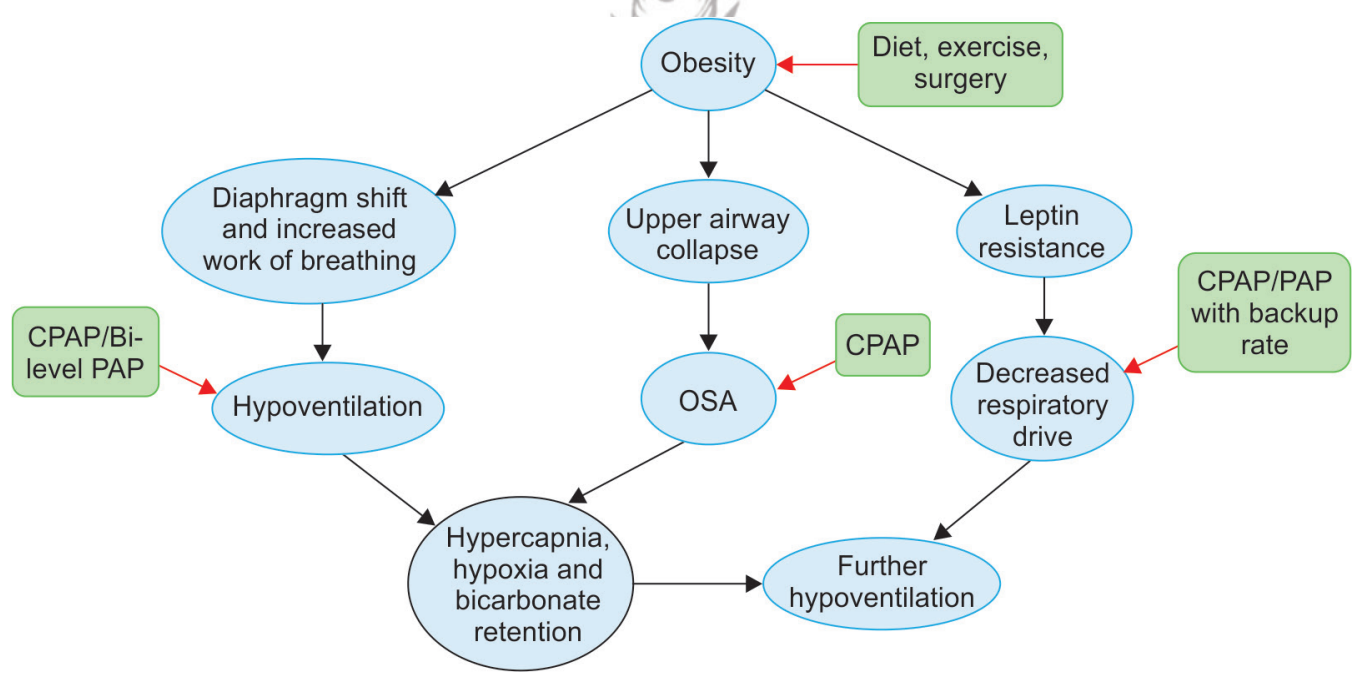

Table 2: Phenotypes of OSA in various age-groups

\begin{tabular}{lll}
\hline No & Phenotype of OSA & Treatment \\
\hline 1 & Childhood OSA & Oral devices and surgery \\
& Craniofacial abnormalities & \\
& Adenotonsillar enlargement & Adenotonsillectomy \\
& Macroglossia & \\
& Retrognathia/prognathia & Tongue retaining device/genioglossus and hyoid advancement, \\
& Avulophrngopalatoplasty, maxillomandibular advancement surgery \\
\hline 2 & -obesity & Pap therapy and target weight control \\
& Late adult onset & Cpap/Bpap(S)/Bpap(S/T) \\
\hline 3 & Rostral fluid shift-CHF/CKD & Treat the cause \\
& Obesity & Drug therapy optimization \\
& Low arousal threshold & Pap \\
& Hyporesponsive genioglossus & Drugs/Bpap (S/T) \\
& Nerve stimulation \\
\hline
\end{tabular}


difficult to treat like retrognathia which requires bone expansion and oral devices. Weight reduction can reduce CPAP requirement in obese people. AASM guidelines recommend a repeat titration in 10 percent weight loss. However, our case highlights that even a complete cure can be targeted in such cases as obesity is the mother illness and the basis of the various pathophysiology in such patients (Flow chart 1).

Thus, in the modern era of phenotyping COPD/bronchial asthma, there is an unmet need of phenotyping OSA, as some phenotypes, including children with adenotonsillar enlargement, and especially obesity-induced obstructive apnea with hypoventilation in the young may be curable.

\section{References}

1. Al Dabal L, BaHammam AS. Obesity hypoventilation syndrome. Ann Thorac Med 2009;4:41-49.

2. Kessler R, Chaouat A, Schinkewitch P, Faller M, Casel S, Krieger J, et al. The obesity-hypoventilation syndrome revisited: a prospective study of 34 consecutive cases. Chest. 2001 Aug 1;120(2):369-376.
3. Laaban J-P, Chailleux E. Observatory Group of ANTADIR. Daytime hypercapnia in adult patients with obstructive sleep apnea syndrome in France, before initiating nocturnal nasal continuous positive airway pressure therapy. Chest 2005;127:710-715.

4. Mokhlesi B, Tulaimat A, Faibussowitsch I, Wang Y, Evans A. Obesity hypoventilation syndrome: prevalence and predictors in patients with obstructive sleep apnea. Sleep Breath 2007;11:117-124.

5. Kaw R, Hernandez AV, Walker E, Aboussouan L, Mokhlesi B. Determinants of hypercapnia in obese patients with obstructive sleep apnea: a systematic review and metaanalysis of cohort studies. Chest 2009;136:787-796.

6. Mokhlesi B, Saager L, Kaw RQ. Should we routinely screen for hypercapnia in sleep apnea patients before elective non cardiac surgery? Cleve Clin J Med 2010;77:60-61.

7. Nowbar S, Burkart KM, Gonzales R, Fedorowicz A, Gozansky WS, Gaudio JC, et al. Obesity associated hypoventilation in hospitalised patients: prevalence, impact and outcome. Am J Med 2004;116:1-7.

8. Subramani Y, Singh M, Wong J, Kushida CA, Malhotra A, Chung F Understanding Phenotypes of Obstructive Sleep Apnea: Applications in Anesthesia, Surgery, and Perioperative Medicine. Anesth Analg. 2017;124(1):179-191.

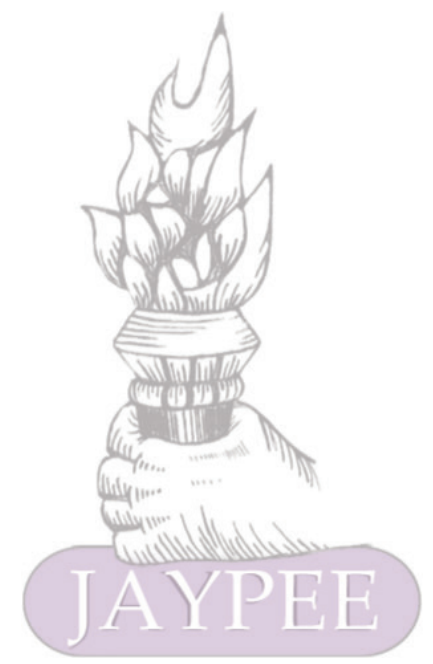

